\title{
Repurposing Screens of FDA-Approved Drugs Identify 29 Inhibitors of SARS-CoV-2
}

\author{
Keun Bon Ku ${ }^{\dagger}$, Hye Jin Shin ${ }^{\dagger}$, Hae Soo Kim, Bum-Tae Kim, Seong-Jun Kim*, and Chonsaeng Kim* \\ Center for Convergent Research of Emerging Virus Infection, Korea Research Institute of Chemical Technology, \\ Daejeon 34114, Republic of Korea
}

\begin{abstract}
COVID-19, caused by the novel coronavirus SARS-CoV-2, has spread globally and caused serious social and economic problems. The WHO has declared this outbreak a pandemic. Currently, there are no approved vaccines or antiviral drugs that prevent SARS-CoV-2 infection. Drugs already approved for clinical use would be ideal candidates for rapid development as COVID-19 treatments. In this work, we screened 1,473 FDA-approved drugs to identify inhibitors of SARS-CoV-2 infection using cell-based assays. The antiviral activity of each compound was measured based on the immunofluorescent staining of infected cells using anti-dsRNA antibody. Twenty-nine drugs among those tested showed antiviral activity against SARS-CoV-2. We report this new list of inhibitors to quickly provide basic information for consideration in developing potential therapies.
\end{abstract}

Keywords: SARS-CoV-2, COVID-19, FDA-approved drugs, repurposing screens

\section{Introduction}

The recent spread of severe acute respiratory syndrome coronavirus 2 (SARS-CoV-2) has caused an outbreak of the emerging disease COVID-19 (coronavirus disease 2019) [1]. The World Health Organization (WHO) declared this outbreak a pandemic in March 2020 [2]. This pandemic is causing serious social and economic problems [3]. The symptoms of COVID-19 patients vary widely, from mild illness to severe diseases including dyspnea, pneumonia, and ultimately death [4-6]. SARS-CoV-2 belongs to the $\beta$ coronaviruses, two of which are potentially fatal, Middle East respiratory syndrome coronavirus (MERS-CoV) and SARS-CoV [7-9]. No effective vaccines or antiviral drugs are currently available, although they are urgently needed. Conventional drug development is a costly and time-consuming process that probably will not be able to achieve timely development of COVID-19 drugs. Drug repurposing is an alternative approach, able to rapidly identify new treatments for COVID-19 [10]. Drugs already approved for clinical use would be ready for use sooner, owing to their established safety profile and pharmacokinetics. Anti-HIV drugs and remdesivir, a nucleotide analogue, have been tested for the treatment of COVID-19 [11,12].

In this study we screened 1,473 food and drug administration (FDA)-approved drugs using a cell-based assay of

Received: September 9,2020 Accepted: November 9,2020

First published online: November 11,2020

*Corresponding authors C.Kim

Phone: +82-42-860-7491

E-mail: chonskim@krict.re.kr

S-J.Kim

Phone: +82-42-860-7477

E-mail: sekim@krict.re.kr

${ }^{\dagger}$ These authors contributed equally to this work.

pISSN 1017-7825 eISSN 1738-8872

Copyright@ 2020 by The Korean Society for

Microbiology and

Biotechnology
SARS-CoV-2 infection. This screening identified 29 drugs with anti-viral effect against SARS-CoV-2. This study offers a new list of drugs for consideration as potential therapies.

\section{Materials and Methods}

Viruses and Cells

SARS-CoV-2 (BetaCoV/Korea/KCDC03/2020) was provided by the Korea Centers for Disease Control and Prevention (NCCP43326). Vero cells (CCL-81) were purchased from the American Type Culture Collection (ATCC) and maintained in Dulbecco's modified Eagle medium (DMEM) supplemented with $10 \%$ fetal bovine serum (both HyClone, USA). SARS-CoV-2 was expanded in the Vero cells and titers were determined by plaque assay. All experiments were performed in a Biosafety Level 3 (BSL3) facility.

\section{Chemical Library and Antibodies}

The FDA-approved drug library of 1,473 drugs and remdesivir were provided by the Korea Chemical Bank at the Korea Research Institute of Chemical Technology (KRICT). The J2 anti-double-stranded RNA (dsRNA) antibody was purchased from English and Scientific Consulting Kft. (Szirák, Hungary, catalog no.10010200). Alexa Fluor 488-conjugated goat anti-mouse antibody was obtained from Life Technologies (USA, catalog no. A11001).

\section{Antiviral Screen}

One day before infection, Vero cells were seeded in 96-well plates at a density of $1 \times 10^{4}$ cells per well. Each compound was added at $20 \mu \mathrm{M}$ final concentration. Cells were then infected with SARS-CoV-2 at an MOI of 0.5. Three days after infection, the cytopathic effects (CPE) of the virus were determined by microscopic examination. 
Drugs showing strong inhibition of viral CPE were selected and their antiviral efficacy was further investigated (see next section).

After optimization of CPE-inhibition assay for screening, Vero cells were seeded as the first screening. Each compound was diluted in DMEM including $1 \mathrm{~g} / \mathrm{mL}$ glucose (low glucose condition) in absence of fetal bovine serum and added to cells at $20 \mu \mathrm{M}$ final concentration. Cells were infected with SARS-CoV-2 at an MOI of 0.5 using the same media used for compound dilution. Three days after infection, cell viability was measured by colorimetric assay using MTS solution (Promega, USA, catalog no. G3582). Assay results from mock infected cells were treated as the $100 \%$ survival standard; those for virus-infected cells in the absence of drugs were considered as the $0 \%$ survival standard. The antiviral activity for each tested drug was calculated as the percentage cell survival by comparison with these standards.

\begin{abstract}
Antiviral Activity and Cell Toxicity Determination
The evaluation of antiviral activity and cell toxicity was conducted on drugs that showed anti-SARS-CoV-2 potential in the antiviral screen described above. We seeded $2 \times 10^{4}$ Vero cells per well in 96-well plates one day before infection. Serially diluted drugs $(100 \mu \mathrm{M}$ to $0.16 \mu \mathrm{M})$ were added to the cells 1 hour prior to infection. The cells were infected with SARS-CoV-2 at an MOI of 2 . At $24 \mathrm{~h}$ post-infection, cells were fixed with $4 \%$ paraformaldehyde and permeabilized with $0.1 \%$ Triton X-100 in phosphate-buffered saline. The cells were then stained with anti-dsRNA antibody and Alexa-Fluor 488-conjugated secondary antibody. Their nuclei were counterstained with Hoechst 33342 (Thermo Fisher Scientific, USA, catalog no. H3570). Image acquisition and analysis were performed as previously described [13]. Viral infection was quantified by dividing the number of cells stained with anti-dsRNA antibody by the total number of cells (obtained by counting the nuclei). Infection rate standards were obtained from mock infected cells (0\%) and drug-free SARS-CoV-2 infected cells (100\%). Infection rates in drug-treated cells were calculated based on these standards. Drug antiviral activity was determined from dose-response curves; half maximal inhibitory concentration $\left(\mathrm{IC}_{50}\right)$ values were calculated using Prism v8 software (GraphPad Software). To determine the cell toxicity $\left(\mathrm{CC}_{50}\right)$, similar experiments were performed without addition of the virus; cell viability was measured using MTS solution. $\mathrm{CC}_{50}$ values were calculated using Prism. The selectivity index (SI) was calculated as $\mathrm{CC}_{50} / \mathrm{IC}_{50}$.
\end{abstract}

\title{
Results and Discussion
}

As SARS-CoV-2 did not efficiently induce cell death, the antiviral assay based on cell survival was unable to produce consistent results. Further optimization to efficiently induce cell death was required in order to measure antiviral activity based on cell survival. However, it was possible to measure the antiviral effect by observing the cells under a microscope. Observations were calibrated using the clear CPE in untreated cells infected with SARSCoV-2 and complete absence of CPE in the presence of the reference compound remdesivir, which has been reported as an inhibitor of SARS-CoV-2 [14]. During the optimization of the antiviral assay, a primary antiviral screening of 1,473 FDA-approved drugs was performed at a final concentration of $20 \mu \mathrm{M}$ based on the microscopic observations. Ten compounds showed strong inhibition of CPE, similar to that seen with remdesivir.

To confirm the antiviral activity of these ten compounds, we used an antiviral assay based on immunofluorescent staining using anti-dsRNA antibody calibrated using a reference compound, remdesivir. This antibody has been used for detection of dsRNA in cells infected with diverse positive-strand RNA viruses including SARS-CoV [15]. As shown in Fig. 1, SARS-CoV-2-infected cells showed a strong fluorescent signal, which gradually decreased in a dose-dependent manner under treatment with remdesivir. The $\mathrm{IC}_{50}$ was $6 \mu \mathrm{M}$. Next, the ten compounds selected by the primary screen were tested over a broader concentration range. All ten candidates showed antiviral activity against SARS-CoV-2 (Table 1 and Fig. 2). The $\mathrm{IC}_{50}$ values are summarized in Table 1, which also shows the cell

A

Uninfected SARS-CoV-2
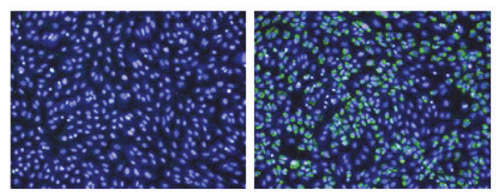

dsRNA

Nuclei

Remdesivir $(\mu \mathrm{M})$

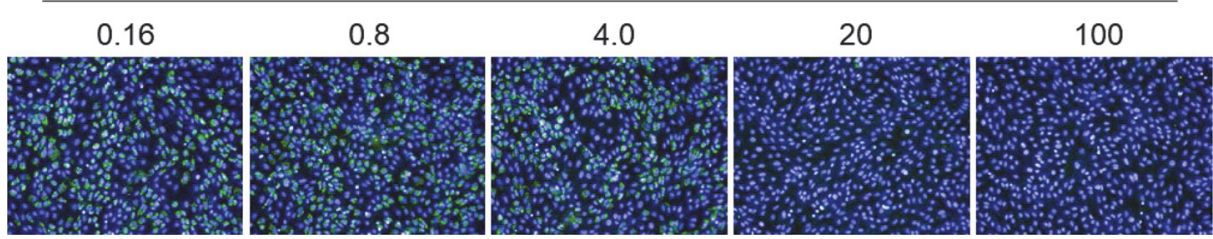

B

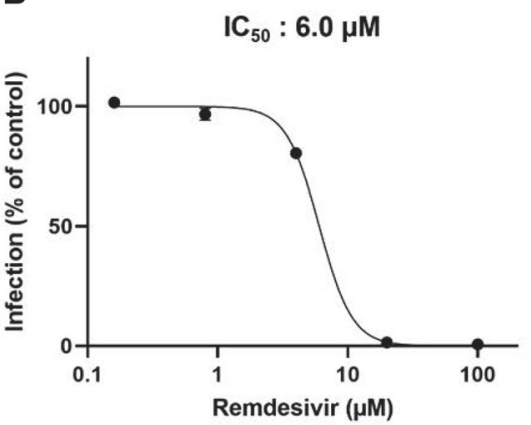

Fig. 1. Antiviral assay based on immunofluorescent staining using anti-dsRNA antibody showed that remdesivir potently inhibits SARSCoV-2 infection. (A) Vero cells were treated with increasing concentrations of remdesivir and infected with SARS-CoV-2 (2 MOI). Twenty-four hours postinfection, infected cells were stained with anti-dsRNA antibody and visualized with Alexa Fluor 488-conjugated secondary antibody (green). Nuclei were stained with Hoechst 33342 (blue). (B) Virus infection was calculated by counting the stained cells and antiviral activity $\left(\mathrm{IC}_{50}\right)$ was determined from the dose-response curve. 
Table 1. Antiviral activity $\left(\mathrm{IC}_{50}\right)$, cell toxicity $\left(\mathrm{CC}_{50}\right)$, and selectivity index $(\mathrm{SI})$ of 10 compounds selected by the primary screening with remdesivir as a positive control.

\begin{tabular}{lccc}
\hline Drug name & $\mathrm{IC}_{50}(\mu \mathrm{M})$ & $\mathrm{CC}_{50}(\mu \mathrm{M})$ & Selectivity Index $(\mathrm{SI})$ \\
\hline Flunarizine & 5.3 & $>100$ & $>18.9$ \\
Micafungin & 5.5 & $>100$ & $>18.1$ \\
Amodiaquine & 5.8 & $>100$ & $>17.2$ \\
Meclizine & 5.6 & $>100$ & $>17.9$ \\
Lomerizine & 12.8 & $>100$ & $>7.8$ \\
Buclizine & 19.6 & $>100$ & $>5.1$ \\
Beclamide & 72 & $>100$ & $>1.4$ \\
Losartan & 72 & 56.3 & $>1.4$ \\
Salinomycin & 0.58 & 74.8 & 97.1 \\
Celecoxib & 17.5 & $>100$ & 4.3 \\
Remdesivir & 5.0 & & $>20$ \\
\hline
\end{tabular}

Flunarizine $(\mu \mathrm{M})$

\begin{tabular}{|c|c|c|c|c|}
\hline 0.16 & 0.8 & 4.0 & 20 & 100 \\
\hline
\end{tabular}

Micafungin $(\mu \mathrm{M})$

\begin{tabular}{|c|c|c|c|c|}
\hline 0.16 & 0.8 & 4.0 & 20 & 100 \\
\hline
\end{tabular}

Amodiaquine $(\mu \mathrm{M})$

\begin{tabular}{|c|c|c|c|c|}
\hline 0.16 & 0.8 & 4.0 & 20 & 100 \\
\hline
\end{tabular}

Meclizine $(\mu \mathrm{M})$

\begin{tabular}{|c|c|c|c|c|}
\hline 0.16 & 0.8 & 4.0 & 20 & 100 \\
\hline
\end{tabular}

Flunarizine_IC $\mathrm{C}_{50}: 5.3 \mu \mathrm{M}$

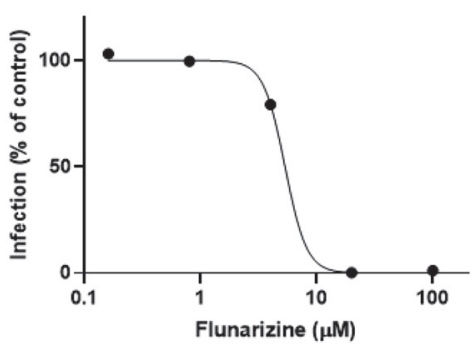

Micafungin_IC ${ }_{50}: 5.5 \mu \mathrm{M}$

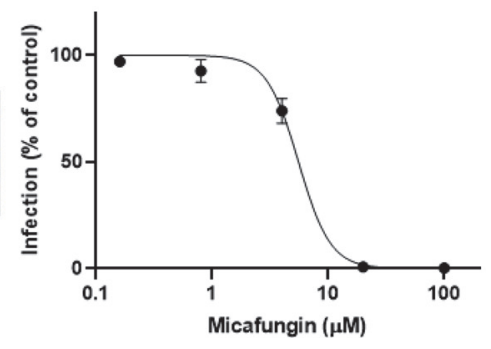

Amodiaquine_IC ${ }_{50}: 5.8 \mu \mathrm{M}$

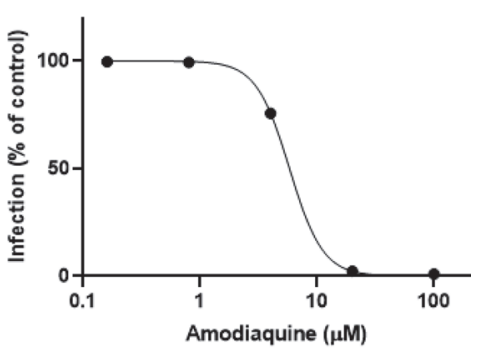

Meclizine_IC ${ }_{50}: 5.6 \mu \mathrm{M}$

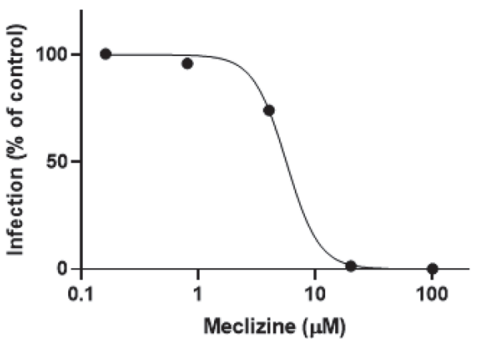

Fig. 2. Dose-response curve of 10 compounds selected by the primary screening with remdesivir as a positive control. The microscope images show cell nuclei (blue) and dsRNA (green) at each drug concentration. 
Lomerizine $(\mu \mathrm{M})$

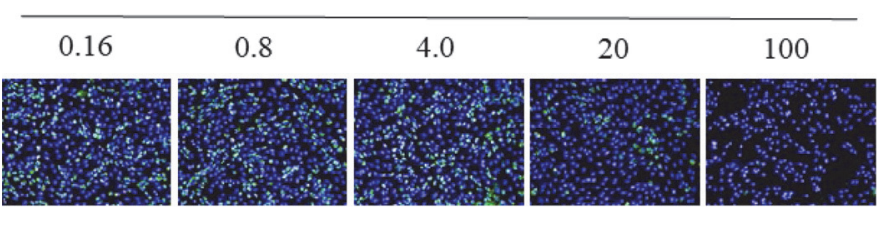

Buclizine $(\mu \mathrm{M})$

\begin{tabular}{|c|c|c|c|c|}
\hline 0.16 & 0.8 & 4.0 & 20 & 100 \\
\hline
\end{tabular}

Beclamide $(\mu \mathrm{M})$

\begin{tabular}{|c|c|c|c|c|}
\hline 0.16 & 0.8 & 4.0 & 20 & 100 \\
\hline
\end{tabular}

Losartan $(\mu \mathrm{M})$

\begin{tabular}{|c|c|c|c|c|}
\hline 0.16 & 0.8 & 4.0 & 20 & 100 \\
\hline
\end{tabular}

Salinomycin $(\mu \mathrm{M})$

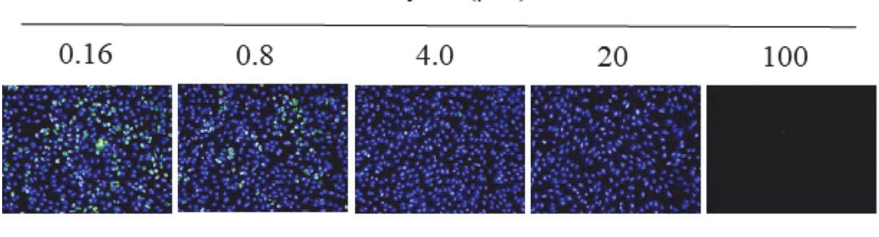

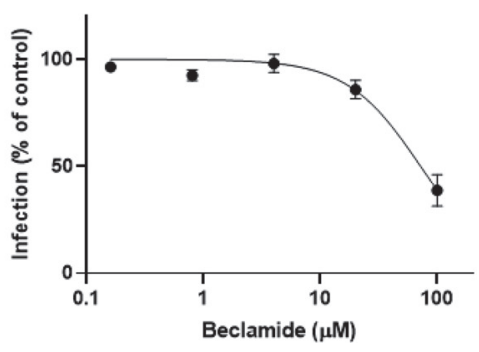

Losartan_IC ${ }_{50}: 72.0 \mu \mathrm{M}$

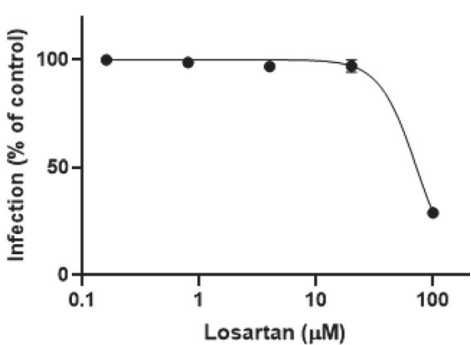

Salinomycin_IC ${ }_{50}: 0.58 \mu \mathrm{M}$

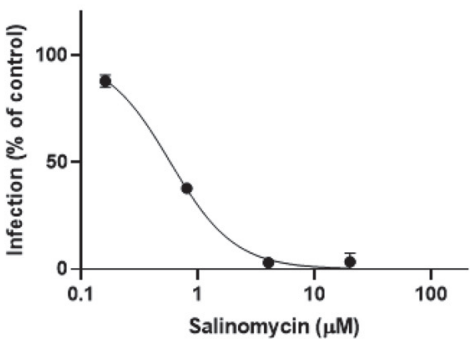

Fig. 2. Continued.

toxicity $\left(\mathrm{CC}_{50}\right)$ and selectivity index (SI) values for these ten compounds.

The compounds were flunarizine, micafungin, amodiaquine, meclizine, lomerizine, buclizine, beclamide, losartan, salinomycin, and celecoxib. Flunarizine is a calcium channel blocker and a prophylactic drug for migraine [16]. Lomerizine is a voltage-dependent calcium channel antagonist and is also used as a prophylactic 
Celecoxib $(\mu \mathrm{M})$

\begin{tabular}{|c|c|c|c|c|}
\hline 0.16 & 0.8 & 4.0 & 20 & 100 \\
\hline
\end{tabular}

Remdesivir $(\mu \mathrm{M})$

\begin{tabular}{|c|c|c|c|c|}
\hline 0.16 & 0.8 & 4.0 & 20 & 100 \\
\hline
\end{tabular}

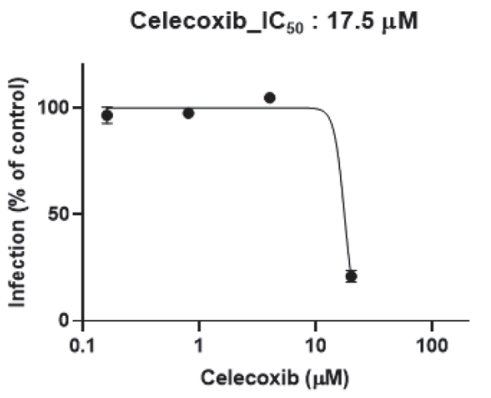

Remdesivir_IC ${ }_{50}: 5.0 \mu \mathrm{M}$

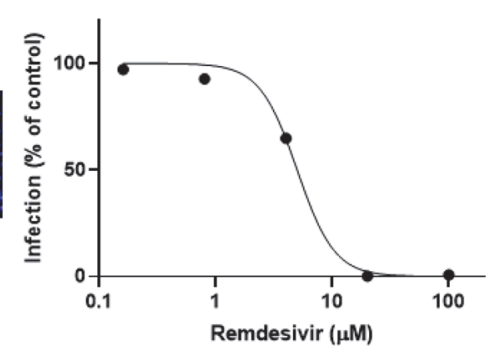

Fig. 2. Continued.

drug for migraines [17]. Previous reports, based on screenings of FDA-approved drugs, have identified flunarizine and lomerizine as inhibitors of Japanese encephalitis virus [18]. Flunarizine is able to inhibit hepatitis C virus cell entry and membrane fusion [19] and lomerizine has shown antiviral activity against Ebola virus [20]. Interestingly, it was recently reported that calcium ions directly interact with the Ebola virus fusion peptide to enhance viral infection; calcium-interfering drugs could therefore be used as therapeutics for this virus [21]. Our results and previous reports suggest that calcium ions could also be important for SARS-CoV-2 entry and membrane fusion. Meclizine and buclizine have been widely used to treat motion sickness and are piperazinederived histamine H1 antagonists [22-24]. There are no reports on the antiviral effects of these two drugs. Flunarizine, lomerizine, meclizine, and buclizine are similar in structure, with a piperazine moiety. Further analysis of the structure-activity relationships of these four inhibitors would be helpful in understanding the molecular structure responsible for their antiviral activity against SARS-CoV-2.

To increase the cell survival differential between mock-infected cells and virus-infected cells, we used DMEM with low glucose and without fetal bovine serum as a dilution medium for both drug and virus. This method
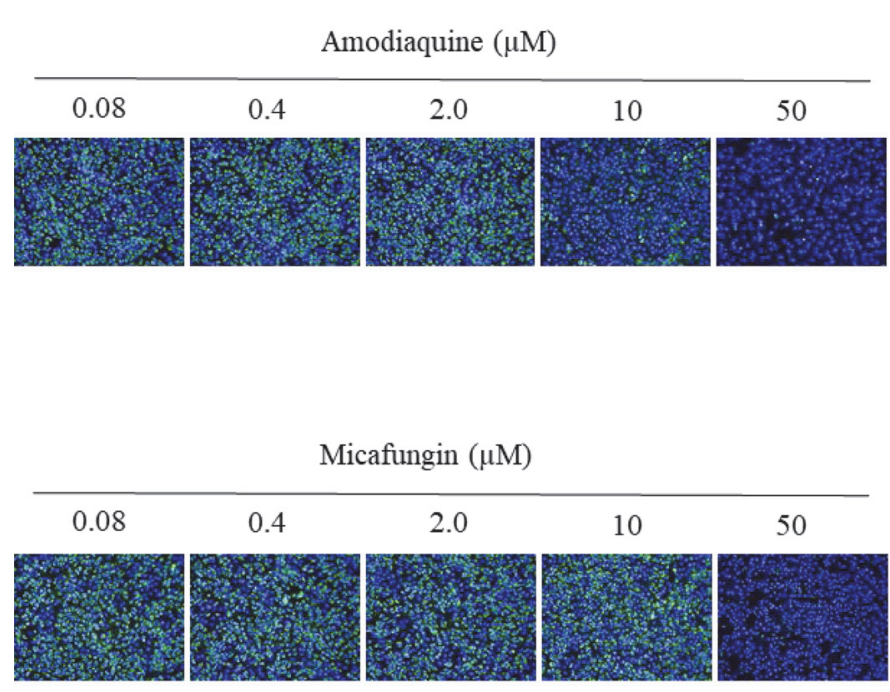

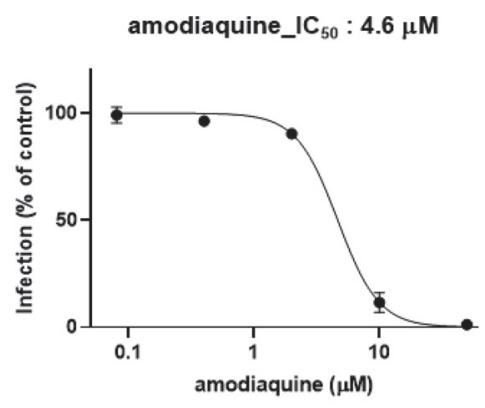

Micafungin_IC ${ }_{50}: \mathbf{1 2 . 9} \mu \mathrm{M}$

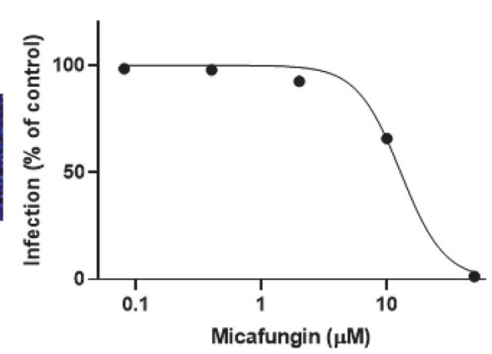

Fig. 3. Dose-response curve of 21 compounds selected by the secondary screening with remdesivir as a positive control. The microscope images show cell nuclei (blue) and dsRNA (green) at each drug concentration. 
Tiratricol $(\mu \mathrm{M})$

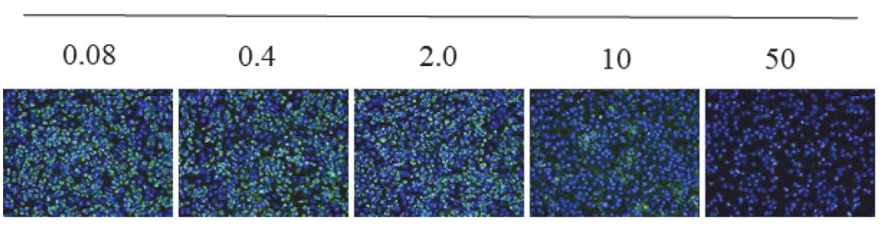

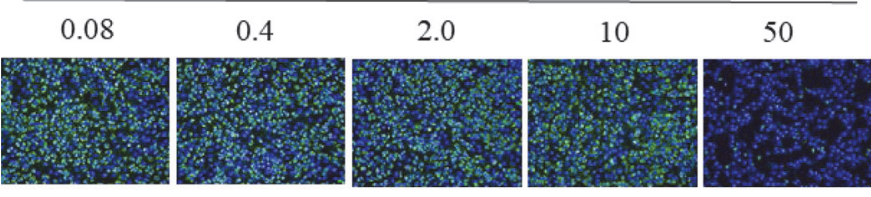

Thioproperazine dimesylate $(\mu \mathrm{M})$

\begin{tabular}{|c|c|c|c|c|}
\hline 0.08 & 0.4 & 2.0 & 10 & 50 \\
\hline
\end{tabular}

Selexipag $(\mu \mathrm{M})$

\begin{tabular}{|c|c|c|c|c|}
\hline 0.08 & 0.4 & 2.0 & 10 & 50 \\
\hline
\end{tabular}

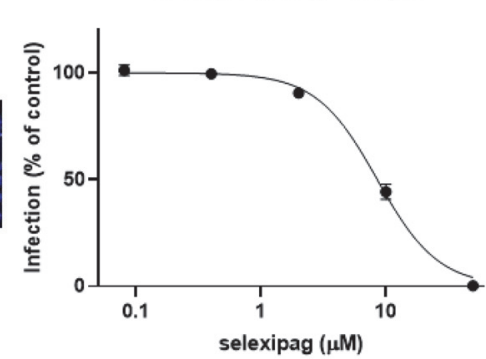

Imatinib $(\mu \mathrm{M})$

\begin{tabular}{ccccc}
\multicolumn{5}{c}{ Imatinib $(\mu \mathrm{M})$} \\
\hline \\
\hline
\end{tabular}

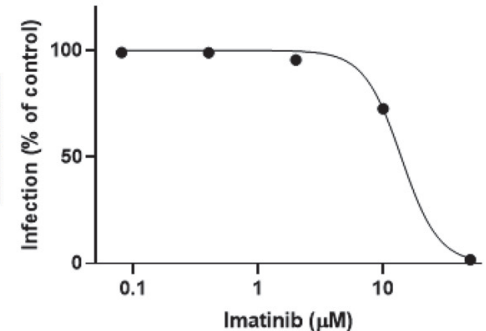

Fig. 3. Continued.

produced a $Z^{\prime}$-factor of 0.62 , which was considered adequate. $Z^{\prime}$-factor is a statistical parameter that is used to assess the quality of the screening. After this optimization process, a secondary antiviral screen was performed. Twenty-six compounds showed at least $60 \%$ inhibition of virus-induced CPE. These were tested over a broader concentration range $(0.08-50 \mu \mathrm{M})$. Among the 26 compounds, 21 showed antiviral activity based on 
Asenapine $(\mu \mathrm{M})$

\begin{tabular}{|c|c|c|c|c|}
\hline 0.08 & 0.4 & 2.0 & 10 & 50 \\
\hline
\end{tabular}

Quinidine gluconate $(\mu \mathrm{M})$

\begin{tabular}{|c|c|c|c|c|}
\hline 0.08 & 0.4 & 2.0 & 10 & 50 \\
\hline
\end{tabular}

Hydroquinidine ( $\mu \mathrm{M})$

\begin{tabular}{|c|c|c|c|c|}
\hline 0.08 & 0.4 & 2.0 & 10 & 50 \\
\hline
\end{tabular}

Masitinib $(\mu \mathrm{M})$

\begin{tabular}{|c|c|c|c|c|}
\hline 0.08 & 0.4 & 2.0 & 10 & 50 \\
\hline
\end{tabular}

Vinpocetine $(\mu \mathrm{M})$

\begin{tabular}{|c|c|c|c|c|}
\hline 0.08 & 0.4 & 2.0 & 10 & 50 \\
\hline
\end{tabular}

Fig. 3. Continued.

immunofluorescent staining (Fig. 3). Their $\mathrm{IC}_{50}$ values are given in Table 2, with their cell toxicity $\left(\mathrm{CC}_{50}\right)$ and selectivity index (SI) values. These 21 compounds were amodiaquine, micafungin, tiratricol, loperamide hydrochloride, thioproperazine dimesylate, selexipag, imatinib, asenapine, quinidine gluconate, hydroquinidine, masitinib, vinpocetine, diphenylpyraline hydrochloride, reserpine, NKH 477, promethazine hydrochloride, 
Diphenylpyraline hydrochloride $(\mu \mathrm{M})$

\begin{tabular}{|c|c|c|c|c|}
\hline 0.08 & 0.4 & 2.0 & 10 & 50 \\
\hline
\end{tabular}

Reserpine $(\mu \mathrm{M})$

\begin{tabular}{|c|c|c|c|c|}
\hline 0.08 & 0.4 & 2.0 & 10 & 50 \\
\hline
\end{tabular}

NKH $477(\mu \mathrm{M})$

\begin{tabular}{|c|c|c|c|c|}
\hline 0.08 & 0.4 & 2.0 & 10 & 50 \\
\hline
\end{tabular}

\begin{tabular}{c|ccccc}
\hline 0.08 & 0.4 & 2.0 & 10 & 50 \\
& & & & & \\
& & & & & \\
& & & & & \\
& & & & & \\
& & & &
\end{tabular}

\begin{tabular}{|c|c|c|c|c|}
\hline 0.08 & 0.4 & 2.0 & 10 & 50 \\
\hline
\end{tabular}

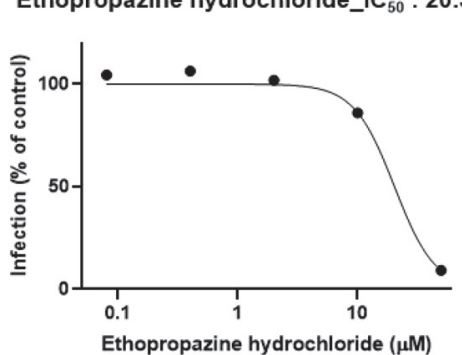

Diphenylpyraline hydrochloride_IC $\mathrm{C}_{50}: \mathbf{4 2 . 4} \mu \mathrm{M}$

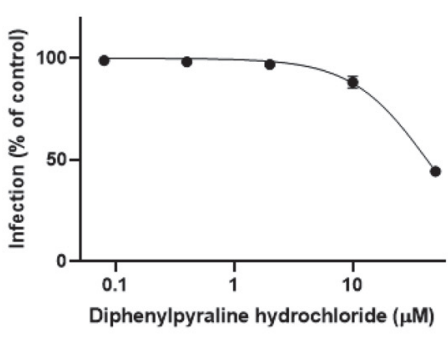

Reserpine_IC ${ }_{50}: 29.2 \mu \mathrm{M}$

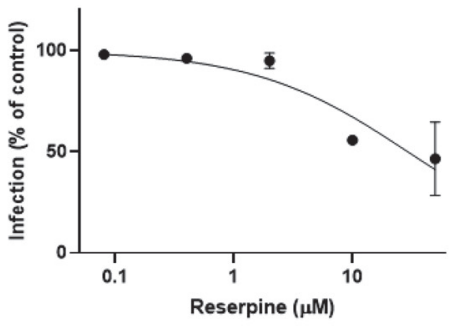

NKH $477 I_{-} C_{50}: 12.7 \mu \mathrm{M}$

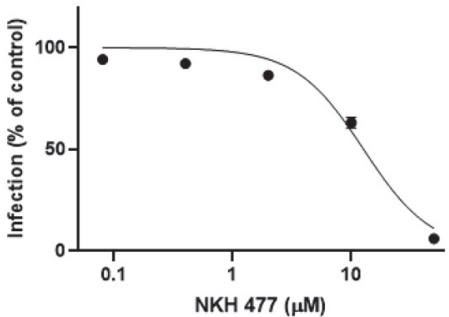

Promethazine hydrochloride_IC ${ }_{50}: 19.1 \mu \mathrm{M}$

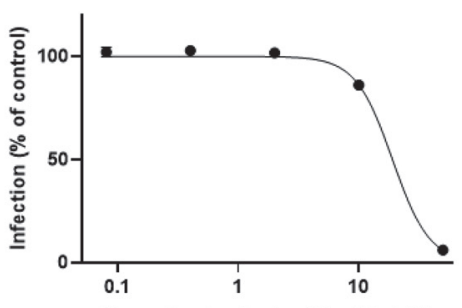

Promethazine hydrochlroride ( $\mu \mathrm{M})$

Ethopropazine hydrochloride_IC ${ }_{50}: 20.3 \mu \mathrm{M}$

Ethopropazine hydrochloride $(\mu \mathrm{M})$

Fig. 3. Continued.

ethopropazine hydrochloride, eltrombopag, vemurafenib (PLX4032), bromhexine hydrochloride, and dibucaine hydrochloride.

Two compounds, amodiaquine and micafungin, were selected in both the primary and secondary screens. Amodiaquine is an anti-malaria drug, but it is also active against several viruses, including dengue virus, zika virus, MERS-CoV, and SARS-CoV [25-27]. Micafungin is an echinocandin with anti-fungal activity, which inhibits the $\beta$-1,3-D-glucan synthase of fungi $[28,29]$. Antiviral activity against enterovirus and chikungunya virus has 

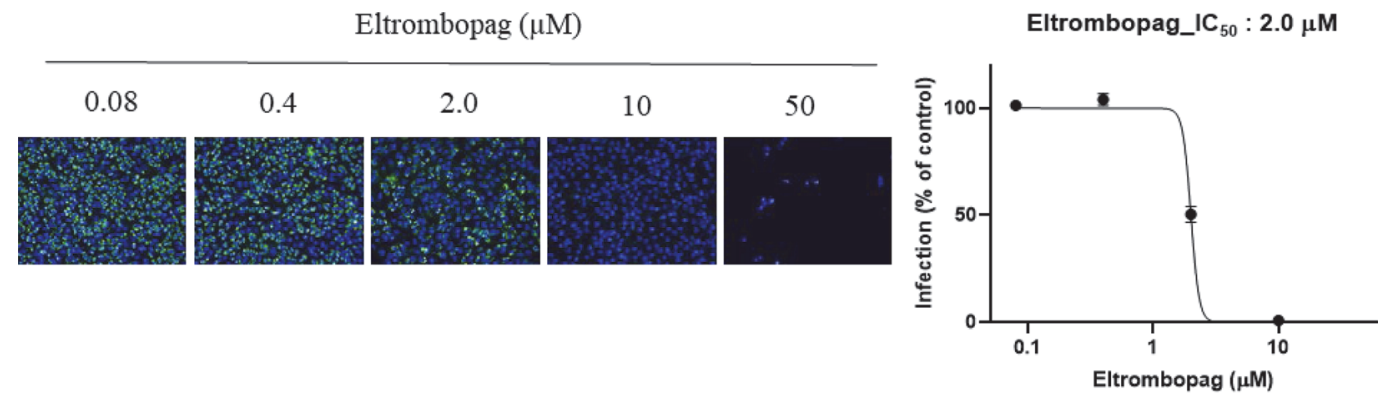

Vemurafenib (PLX4032) ( $\mu \mathrm{M})$

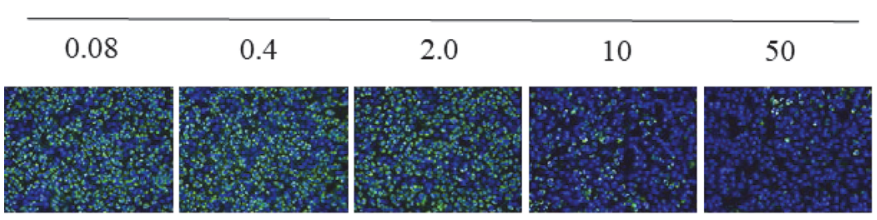

Bromhexine hydrochloride $(\mu \mathrm{M})$

\begin{tabular}{|c|c|c|c|c|}
\hline 0.08 & 0.4 & 2.0 & 10 & 50 \\
\hline
\end{tabular}

Dibucaine hydrochloride $(\mu \mathrm{M})$

\begin{tabular}{|c|c|c|c|c|}
\hline 0.08 & 0.4 & 2.0 & 10 & 50 \\
\hline
\end{tabular}

Remdesivir $(\mu \mathrm{M})$

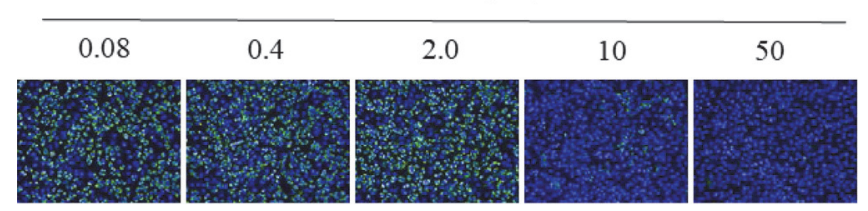

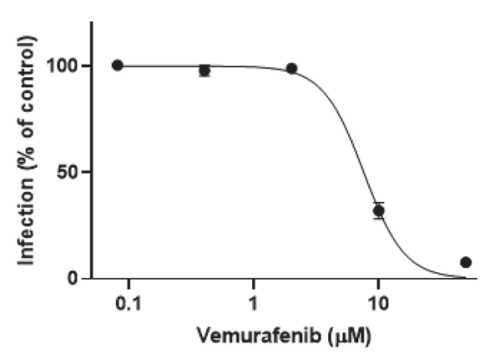

Bromhexine hydrochloride_I $\mathrm{C}_{50}: 14.4 \mu \mathrm{M}$

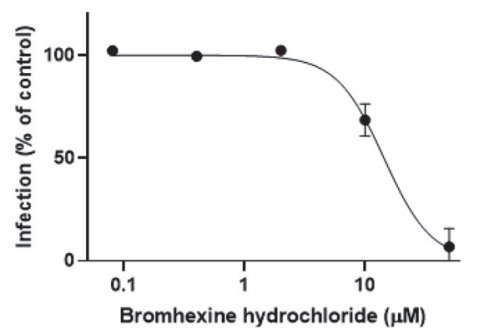

Dibucaine hydrochloride_IC $C_{50}: 21.6 \mu \mathrm{M}$

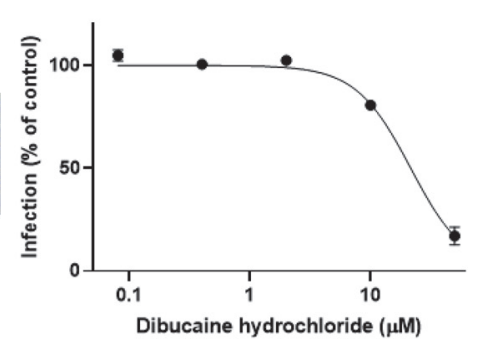

Remdesivir_IC $50: 5.0 \mu \mathrm{M}$

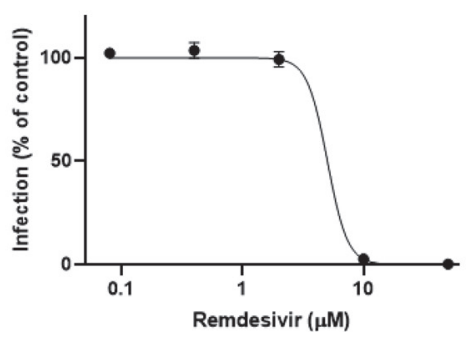

Fig. 3. Continued.

been reported [30, 31]. This is the first demonstration of antiviral activity of micafungin against SARS-CoV-2.

Bromhexine hydrochloride is an inhibitor of TMPRSS2, a cofactor of SARS-CoV-2 entry, and one group reported that the drug was effective on COVID-19 patients in a clinical trial [32]. To further investigate whether bromhexine hydrochloride could inhibit SARS-CoV-2 replication, viral RNA was measured by real-time RT-PCR using primer sets specific to $\mathrm{N}$ gene of SARS-CoV-2. The treatment of this drug on virus-infected cells effectively 
Table 2. Antiviral activity $\left(\mathrm{IC}_{50}\right)$, cell toxicity $\left(\mathrm{CC}_{50}\right)$, and selectivity index (SI) of 21 compounds selected by the secondary screening with remdesivir as a positive control.

\begin{tabular}{lccc}
\hline \multicolumn{1}{c}{ Drug name } & $\mathrm{IC}_{50}(\mu \mathrm{M})$ & $\mathrm{CC}_{50}(\mu \mathrm{M})$ & Selectivity Index $(\mathrm{SI})$ \\
\hline Amodiaquine & 4.6 & $>50$ & $>10.9$ \\
Micafungin & 12.9 & $>50$ & $>3.9$ \\
Tiratricol & 4.6 & $>50$ & $>10.9$ \\
Loperamide hydrochloride & 14.8 & $>50$ & $>3.4$ \\
Thioproperazine dimesylate & 13.4 & $>1$ & $>5.9$ \\
Selexipag & 8.5 & $>50$ & $>3.6$ \\
Imatinib & 13.9 & $>50$ & $>3.8$ \\
Asenapine & 13.3 & $>50$ & $>2.1$ \\
Quinidine gluconate & 24.2 & $>50$ & 3.1 \\
hydroquinidine & 23.8 & 47.1 & $>5.8$ \\
Masitinib & 14.9 & $>50$ & $>1.2$ \\
Vinpocetine & 8.6 & $>50$ & $>1.7$ \\
Diphenylpyraline hydrochloride & 42.4 & $>50$ & $>3.9$ \\
Reserpine & 29.2 & $>50$ & $>2.6$ \\
NKH 477 & 12.7 & $>50$ & $>2.5$ \\
Promethazine hydrochloride & 19.1 & $>50$ & 21.9 \\
Ethopropazine hydrochloride & 20.3 & 43.8 & $>7.1$ \\
Eltrombopag & 2.0 & $>50$ & $>3.5$ \\
Vemurafenib (PLX4032) & 7.0 & $>50$ & $>2.3$ \\
Bromhexine hydrochloride & 14.4 & $>50$ & $>10$ \\
Dibucaine hydrochloride & 21.6 & &
\end{tabular}

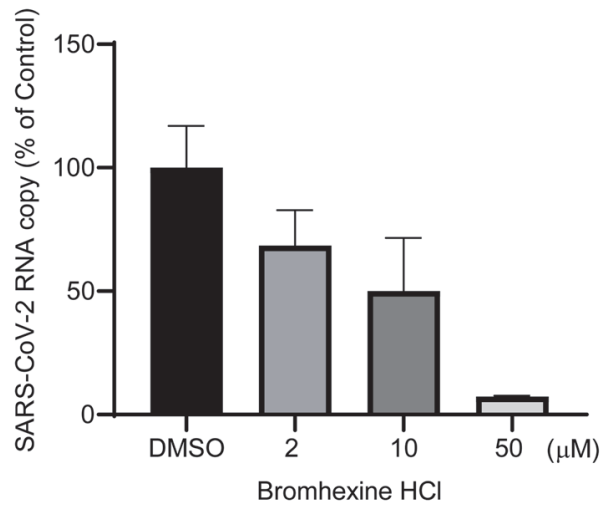

Fig. 4. Suppression of SARS-CoV-2 replication by bromhexine hydrochloride. Cellular RNAs were isolated from cells infected by SARS-COV-2 and treated with bromhexine hydrochloride. The level of viral RNA was measured by real-time RT-PCR using primer sets specific to $\mathrm{N}$ gene of SARS-CoV-2.

reduced the intracellular RNA (Fig. 4).

Salinomycin and eltrombopag showed lower $\mathrm{IC}_{50}$ with good SI compared to remdesivir. Salinomycin, an antibiotic against gram-positive bacteria, also showed anti-viral effect on MERS-CoV and SARS-CoV [33, 34]. This drug was supposed to inhibit the endosomal acidification and the entry of viruses into cells. The thrombopoietin-receptor agonist eltrombopag has been used for the treatment of thrombocytopenia and showed antiviral effect on human cytomegalovirus via iron chelation [35]. There has been no report, however, on this drug having anti-viral activity against SARS-CoV or MERS-CoV. It would be interesting to investigate the target and mode-of-action of eltrombopag.

Overall, we identified 29 drugs that showed antiviral activity against SARS-CoV-2. Although further studies are required to understand their mode of action and confirm their efficacy in animal models, we now report this list of SARS-CoV-2 inhibitors to provide valuable basic information in the developmental support of potential therapeutic options.

\section{Acknowledgments}

The FDA-approved drug library was kindly provided by the Korea Chemical Bank at Korea Research Institute of Chemical Technology (KRICT). SARS-CoV-2 (NCCP43326) was kindly provided by the National Culture Collection for Pathogens at the Korea Centers for Disease Control and Prevention. This research was supported by a National Research Council of Science and Technology (NST) grant through the Korean government (MSIP) (CRC-16-01-KRICT) 


\section{Conflict of Interest}

The authors have no financial conflicts of interest to declare.

\section{References}

1. Zhou P, Yang XL, Wang XG, Hu B, Zhang L, Zhang W, et al. 2020. A pneumonia outbreak associated with a new coronavirus of probable bat origin. Nature 579: 270-273.

2. Cucinotta D, Vanelli M. 2020. WHO Declares COVID-19 a Pandemic. Acta Biomed. 91: 157-160.

3. Nicola M, Alsafi Z, Sohrabi C, Kerwan A, Al-Jabir A, Iosifidis C, et al. 2020. The socio-economic Implications of the Coronavirus and COVID-19 Pandemic: a review. Int. J. Surg. 78: 185-193.

4. Lake MA. 2020. What we know so far: COVID-19 current clinical knowledge and research. Clin. Med. (Lond) 20: 124-127.

5. Guan WJ, Ni ZY, Hu Y, Liang WH, Ou CQ, He JX, et al. 2020. Clinical characteristics of Coronavirus Disease 2019 in China. N. Engl. J. Med. 382: 1708-1720.

6. Weiss P, Murdoch DR. 2020. Clinical course and mortality risk of severe COVID-19. Lancet 395: 1014-1015.

7. Lee JY, Bae S, Myoung J. 2019. Middle east respiratory syndrome Coronavirus-encoded accessory proteins Impair MDA5-and TBK1-Mediated Activation of NF-kappaB. J. Microbiol. Biotechnol. 29: 1316-1323.

8. Lee JY, Kim SJ, Myoung J. 2019. Middle east respiratory syndrome Coronavirus-encoded ORF8b inhibits RIG-I-Like receptors in a differential mechanism. J. Microbiol. Biotechnol. 29: 2014-2021.

9. Lee J, Bae S, Myoung J. 2019. Generation of full-length infectious cDNA clones of middle east respiratory syndrome Coronavirus. J. Microbiol. Biotechnol. 29: 999-1007.

10. Ashburn TT, Thor KB. 2004. Drug repositioning: identifying and developing new uses for existing drugs. Nat. Rev. Drug Discov. 3: 673-683.

11. Cao B, Wang Y, Wen D, Liu W, Wang J, Fan G, et al. 2020. A trial of lopinavir-ritonavir in adults hospitalized with severe Covid-19. N. Engl. J. Med. 382: 1787-1799.

12. Grein J, Ohmagari N, Shin D, Diaz G, Asperges E, Castagna A, et al. 2020. Compassionate use of remdesivir for patients with severe Covid-19. N. Engl. J. Med. 382: 2327-2336.

13. Kim HS, Lee K, Kim SJ, Cho S, Shin HJ, Kim C, et al. 2018. Arrayed CRISPR screen with image-based assay reliably uncovers host genes required for coxsackievirus infection. Genome Res. 28: 859-868.

14. Wang M, Cao R, Zhang L, Yang X, Liu J, Xu M, et al. 2020. Remdesivir and chloroquine effectively inhibit the recently emerged novel coronavirus (2019-nCoV) in vitro. Cell Res. 30: 269-271.

15. Weber F, Wagner V, Rasmussen SB, Hartmann R, Paludan SR. 2006. Double-stranded RNA is produced by positive-strand RNA viruses and DNA viruses but not in detectable amounts by negative-strand RNA viruses. J. Virol. 80: 5059-5064.

16. Amery WK. 1983. Flunarizine, a calcium channel blocker: a new prophylactic drug in migraine. Headache 23: 70-74.

17. Ishii M, Kobayashi S, Ohkura M, Yamamoto R, Shimizu S, Kiuchi Y. 2009. Inhibitory effect of lomerizine, a prophylactic drug for migraines, on serotonin-induced contraction of the basilar artery. J. Pharmacol. Sci. 111: 221-225.

18. Wang S, Liu Y, Guo J, Wang P, Zhang L, Xiao G, et al. 2017. Screening of FDA-Approved drugs for Inhibitors of Japanese Encephalitis Virus infection. J. Virol. 91: e01055-17.

19. Perin PM, Haid S, Brown RJ, Doerrbecker J, Schulze K, Zeilinger C, et al. 2016. Flunarizine prevents hepatitis C virus membrane fusion in a genotype-dependent manner by targeting the potential fusion peptide within E1. Hepatology 63: 49-62.

20. Johansen LM, DeWald LE, Shoemaker CJ, Hoffstrom BG, Lear-Rooney CM, Stossel A, et al. 2015. A screen of approved drugs and molecular probes identifies therapeutics with anti-Ebola virus activity. Sci. Transl. Med. 7: 290ra289.

21. Nathan L, Lai AL, Millet JK, Straus MR, Freed JH, Whittaker GR, et al. 2020. Calcium ions directly interact with the Ebola virus fusion peptide to promote structure-function changes that enhance infection. ACS Infect. Dis. 6: 250-260.

22. Wibble T, Engstrom J, Verrecchia L, Pansell T. 2020. The effects of meclizine on motion sickness revisited. Br. J. Clin. Pharmacol. 86: $1510-1518$.

23. Guo J, Li W, Wu Y, Jing X, Huang J, Zhang J, et al. 2017. Meclizine prevents ovariectomy-induced bone loss and inhibits osteoclastogenesis partially by upregulating PXR. Front. Pharmacol. 8: 693.

24. Mostafa GA, Al-Badr AA. 2011. Buclizine. Profiles Drug Subst. Excip. Relat. Methodol. 36: 1-33.

25. D’Alessandro S, Scaccabarozzi D, Signorini L, Perego F, Ilboudo DP, Ferrante P, et al. 2020. The use of antimalarial drugs against viral infection. Microorganisms. 8: 85.

26. Han Y, Mesplede T, Xu H, Quan Y, Wainberg MA. 2018. The antimalarial drug amodiaquine possesses anti-ZIKA virus activities. J. Med. Virol. 90: 796-802.

27. Dyall J, Coleman CM, Hart BJ, Venkataraman T, Holbrook MR, Kindrachuk J, et al. 2014. Repurposing of clinically developed drugs for treatment of Middle East respiratory syndrome coronavirus infection. Antimicrob. Agents Chemother. 58: 4885-4893.

28. Pappas PG, Rotstein CM, Betts RF, Nucci M, Talwar D, De Waele JJ, et al. 2007. Micafungin versus caspofungin for treatment of candidemia and other forms of invasive candidiasis. Clin. Infect. Dis. 45: 883-893.

29. Denning DW. 2003. Echinocandin antifungal drugs. Lancet 362: 1142-1151.

30. Kim C, Kang H, Kim DE, Song JH, Choi M, Kang M, et al. 2016. Antiviral activity of micafungin against enterovirus 71 . Virol. J. 13: 99.

31. Ho YJ, Liu FC, Yeh CT, Yang CM, Lin CC, Lin TY, et al. 2018. Micafungin is a novel anti-viral agent of chikungunya virus through multiple mechanisms. Antiviral. Res. 159: 134-142.

32. Ansarin K, Tolouian R, Ardalan M, Taghizadieh A, Varshochi M, Teimouri S, et al. 2020. Effect of bromhexine on clinical outcomes and mortality in COVID-19 patients: A randomized clinical trial. Bioimpacts 10: 209-215.

33. Antoszczak M, Maj E, Napiorkowska A, Stefanska J, Augustynowicz-Kopec E, Wietrzyk J, et al. 2014. Synthesis, anticancer and antibacterial activity of salinomycin N-benzyl amides. Molecules 19: 19435-19459.

34. Ianevski A, Yao R, Fenstad MH, Biza S, Zusinaite E, Reisberg T, et al. 2020. Potential antiviral options against SARS-CoV-2 infection. Viruses 12: 642

35. Vogel JU, Schmidt S, Schmidt D, Rothweiler F, Koch B, Baer P, et al. 2019. The thrombopoietin receptor agonist eltrombopag inhibits human cytomegalovirus replication via iron chelation. Cells $9: 31$. 